\title{
A PHILOSOPHICAL APPROACH TO FOLK CATHOLICISM: A COLLINGWOODIAN EXPLORATION
}

\section{Raymundo R. Pavo University of the Philippines - Mindanao, Philippines}

\begin{abstract}
The principle of overlap of classes holds that when two entities interface, the effect is a blurring of boundaries between conceptual territories. In this paper, this question is in order: Is Folk Catholicism an instance of overlap of classes? If Folk Catholicism is not construed as such, these fallacies - using Robin George Collingwood's perspective in his An Essay on Philosophical Method (1933), may unfold: the fallacy of precarious margins, the fallacy of identified coincidents, and the fallacy of false disjunction. The first fallacy holds that the 'Folk' in Folk Catholicism has no contribution to how 'Catholicism' unfolds. The second fallacy maintains that the extensions of both 'Folk' and 'Catholicism' are clearly delineated. The third fallacy underscores that Folk and Catholicism are mutually exclusive terms. When such fallacies are accepted, this paper holds that Folk Catholicism as a construct may be a contradiction of terms on what it means to be Folk and Catholic. This is the illogical consequence given that the truth of what it means to be folk necessitates the falsity of what it means to be Catholic and vice-versa. However, when recognized from the lens of the overlap, Folk Catholicism is construed as a term that evolves and is historically conditioned.
\end{abstract}

\section{INTRODUCTION}

The principle of the overlap of classes holds a hermeneutical position in Collingwood's philosophy. His philosophical system privileges the principle as it holds together his other equally important discussions on the nature and levels of understanding. In An Essay on Philosophical Method (hereafter, EPM), the scale refers to the transition from lower to higher forms of understanding, while the overlap pertains to the blurring of conceptual boundaries of two thought species. In this case, the principle of the overlap is taken to mean as the necessary condition so higher cognition of concepts or constructs can ensue. More to the point, better cognition happens when the so-called higher understanding can identify the limitations in lower species of thought and correct such weaknesses.

With Collingwood's effort to distinguish lower from higher levels of 
understanding, this paper uses the scale of understanding and the principle of the overlap in deciphering the nature of Folk Catholicism as a concept. What is Folk Catholicism as a philosophic concept? In raising this query, this paper hopes to clarify the philosophical merits of Folk Catholicism as a term, which means explicitly locating the transition from limited to broader forms of understanding of the term. In the paper, such transition is presented in this manner: from one-sided and binary treatment of Folk Catholicism, and Folk Catholicism interpreted as an instance of the overlap of classes.

As a construct, Folk Catholicism can be approached as a philosophical construct in addition to its more familiar historical-sociological and theological treatment and discussion. In order to locate the philosophical presentation, the historical-sociological approach and theological perspective is used to serve as a rational backdrop against which the philosophical discourse can further locate its sense and meaning.

As a theological concept, Folk Catholicism has been interpreted as an instance of split-level Christianity. In this perspective, Folk Catholicism is taken to mean having two unreconciled levels of belief, that is, between faith and traditions. This is where faith is magnified explicitly at the expense of local traditions (Hiebert et al. 1999/2000, 173-182). However, this syncretic stance has been challenged by theologians such as Vergote (1982, 5-26). He notes that in dealing with Folk Religion, the key point is to find lasting truths couched in Folk Catholicism and distinguishing illusory meanings from certain beliefs and practices through critical contextualization. Lynch (1975, 12325), while he expresses worry that local traditions are excluded to the margins, somewhat prescinds the role of Folk Religion by identifying it to the category of nonofficial and tolerated teachings (Schumacher, 1984, 251).

A critical stance towards the concept of split-level Christianity is further presented by Bulatao (1992) and Mojares (1993) as both authors underscore the latent agency intertwined to particularities or locales/localities. These perspectives approach Folk Catholicism from a historical-sociological viewpoint. Ileto (1979, 11-13) also offers an interesting take on Folk Catholicism, which is taken to mean a site where oppression and covert forms of agency occur. While Ileto's position is worthy to note, such stance has been critiqued by Scalice (2018, 50-53), who underscores Ileto's lack of historiographic evidence of the pulse of the masses and the seeming incompatibility between his reading of Pasyon Pilapil and its detachment from the everyday life of the masses vis-à-vis the rising intensity of the $19^{\text {th }}$-century demand for the production of new commodities. This critique offers an insight on the sociological demand to ascertain the role of sound empirical basis in appropriating the grounded/local aspects of folk-related discussions, as is the case in Folk Catholicism.

Given the theological and historical-sociological reading of Folk Catholicism, this paper attempts to introduce a philosophical treatment of the term. This is accomplished by revisiting the binary discussion of Folk Catholicism through Collingwood's principle of the overlap of classes in EPM. Thus, the theological stance of Bulatao (1992) towards a Filipino Theology and Mojares' (1993, 443-45) interrogations of the universalizing texts of the medieval church in Ayatumo's biography is also considered to help locate the philosophical challenge to the eitheror-stance towards Folk Catholicism. As a philosophical endeavor, the intent is to magnify the meaning and logical consequences of the either-or disjunctive logical operator, its untenability, and possible tenability. This paper locates such an attempt 
by forwarding the meaning of Folk Catholicism as a disjunctive term wherein stress is given either to the 'Folk' or 'Catholic' side but at the expense of the other. In the case of Lynch $(1975,237)$, for instance, he opines that the contribution of the 'Folk' part is not properly treated, while for Ileto $(1979,250-51)$, the interpretation of 'Catholic' dimension leans towards the position that it acts as a cloak to the revolutionary genius in the 'Folk' traditions, and as a location for the subversive appropriation of the life of Christ. By looking into both positions, a possible reflection awaits the need to have a proper distinction and a further reflection on the relation between the local church or grounded forms of spirituality and universalizing tendencies of the church.

This paper also presents a philosophical take on the tensions and opposing ideas surrounding the binary treatment of Folk Catholicism to clarify and re-consider the philosophical demands and perhaps other values in the coupling of the terms in Folk Catholicism. The lens of Collingwood is specifically used in order to raise this question: Is Folk Catholicism an instance of a philosophical overlap of classes? Guided by Collingwood's rumination, the question means that Folk Catholicism - in theory, and practice - as two sub-terms cannot be conjoined as mutually exclusive terms. This means that if the elements of 'Folk' and 'Catholic' sides do not interface, the one-sided treatment of the term can be philosophically construed as an unfinished effort of the mind to better cognize or reflect on other ways of thinking about the nature and meaning of Folk Catholicism.

\section{COLLINGWOOD'S THE PRINCIPLE OF THE OVERLAP OF CLASSES}

\section{Between Science and Philosophy}

The EPM differentiates a scientific concept from a philosophic concept. Progressive abstraction is a type of reasoning that may be used to describe a kind of thinking operative in science. More specifically, this form of reasoning is progressive since it needs to build on assumptions or presuppositions. The assumption, in this regard, acts as the ground upon which a system of thought can be built and construed. As a consequence, the starting point of scientific research needs to be assumed as something true and tenable. It acts as the principle that regulates the truth of constructed, hence participating classes of thought.

In empirical science, according to Collingwood, there are two complete starting points or axioms. The first one is "the purely logical principles, which begin by being certain and can never become either more or less so as induction proceeds" (Collingwood 1933a, 166), which is akin to being a presupposition wherein "when we come to consider them, prove not only assumptions but assumptions having little or no inherent plausibility; the most we can say for them is that they are not known to be untrue, and that it is expedient to assume them" (Collingwood 1933a, 166). This axiom in empirical science, for instance, is a supposition that holds that when the empirical scientist conducts his research, he assumes that the particularities he encounters are interrelated in some form. This is a presupposition that the empirical scientist does not question. This is because an investigation of similarities and 
differences among particular phenomena would not make sense if he does not assume that he can discover a principle that can weave, even partially, certain specificities. This is the purely logical principle that conditions the possibility of empirical scientific research.

The second axiom in empirical science holds that "because some $\mathrm{S}$ is $\mathrm{P}$ therefore probably all S is P" (Collingwood 1933a, 166). This suggests that "the future will probably resemble the past, or the known the unknown" (Collingwood 1933a, 166). In hindsight, this stance suggests that empirical science can never produce a type of certainty that is logically necessary. This axiom means that the results of empirical research can never traverse the gap between a probability and a logical necessity. It has to remain content with probabilities (Collingwood 1933a, 167). With both axioms, the empirical scientist can only proceed in his research when such presuppositions are maintained. Unless the axioms are assumed to be true, empirical science could not make an advance in its inquiry. This is the reason why science, the empirical science, for instance, is engaged in progressive thinking.

Regressive abstraction is the type of reasoning that is reflective of the philosophical enterprise. Within the purview of philosophy, thinking proceeds in such a way as it considers its task to cognize better and improve the comprehension of its assumptions and presuppositions. In so doing, philosophizing proceeds in its search when assumptions are treated as the object of the investigation. Consequently, philosophy's entry point is always incomplete and subject to change and modification. This is also the reason why Collingwood maintains that philosophizing follows a reversible direction as philosophy continuously tries to examine its starting point or its presuppositions (Collingwood 1933a, 168). Thus, with the reversible nature of a philosophical inference, it can be said that philosophy follows a regressive type. It is regressive because philosophy can only advance in its investigation if it moves backward, which means that if it studies and reflects the connotation of its own starting points. And when the philosopher has understood the strengths and limitations of his assumptions, he has opened for himself an opportunity to advance or encounter better ways of thinking. Consequently, the philosopher has provided for himself opportune positions to enlarge his current conceptions and move up in his understanding of philosophical thought. As Collingwood (1933a, 170) explains, "Our knowledge is not simply accumulating, it is developing; it is improving as well as increasing, it is widening and strengthening itself at once."

\section{The Principle of the Overlap of Classes}

Since philosophy follows the reversible or regressive mode of thinking, the enterprise of philosophy subsists and grows when it proceeds in the language of the overlap. The overlap, in this respect, is the logical consequence of the reversible relation that philosophy has in relation to its assumptions. What is this principle about? The notion of overlap of classes proposes that a philosophical concept is recalcitrant to precise and mutually exclusive forms of taxonomy. To explain what a philosophical concept is not, let us attempt to show the insufficiency of the precise method of 
classification when applied to a philosophic term. For this purpose, we choose to analyze a frequently used concept in metaphysics: being.

Using Baruch Spinoza's specific treatment of this concept, 'being' is said to possess three predicates: unity, reality, and goodness (Collingwood, 1933a, 149). Using the precise way of classification, the predicates of being should be divided into mutually exclusive species. This way requires a precise line that can demarcate and differentiate the distinctive properties of the three species of being. Thus, the philosopher is expected to clearly know the exact set of features that separates unity from reality, unity from goodness, and goodness from reality and unity. This also implies that the distinctive characteristics of unity are totally exempt from the distinguishing characteristics of reality and goodness. Logically construed, the specific difference of the species goodness does not have to do anything with the distinguishing aspects present in the other species of the genus being. With these demands, we formulate the following questions: Is it possible for a philosopher to fully cognize the conditions that separate the predicate unity from goodness and reality as the other species of being? Is it sound to propose that the distinctive characteristics of unity are totally absent in the intension of reality and goodness?

Collingwood holds that it is problematic to totally exclude the intension of unity from that of reality and goodness. There is difficulty in a statement that proposes that the meaning of the species goodness is completely free of any feature of the predicate unity. When one talks about goodness as a species of being, one cannot deny the fact that it must have an element of unity and reality. Goodness shares in some of the qualities that unity and reality possess. If one talks about the goodness of being, it should also be something unified and real. The difficulty of segregating unity from reality and goodness indicates one feature of a philosophical concept: the characteristics of its species are diffused into the other species of a genus. The predicates of a philosophical concept leak into and influence its adjacent or neighboring regions. The presence of at least one thread that runs through the entire fabric of a genus is a basic feature for an overlapping case. Hence, the nature of a philosophic concept suggests that the characteristics of the participating species of a given genus will never be mutually isolated (Collingwood 1933a, 32-33). Thus, when an overlapping relation is instanced, certain characteristics/elements will always influence its adjacent regions.

The foregoing characterization of the nature of a philosophic concept is an important step in understanding this insight: the essence of a philosophic genus cannot be mutually exhausted by its species. No single species stands as the complete instantiation of a genus in philosophy. Based on our example of the concept of goodness, the insight implies that it is not enough to say that goodness is equivalent to the pleasant. Also, the expedient does not define the meaning of being good. And, the right has no monopoly over the intension of goodness as a philosophical genus. When one philosophically talks about goodness, it entails a unique configuration or combination of certain characteristics present in its three species: the pleasant, the expedient, and the right. For Collingwood (Collingwood 1933a, 32-33), the three predicates or species participate in a philosophical genus of goodness or contributes something to the concept's overall meaning. 


\section{Three Misinterpretations of the Overlap}

Another way of understanding the principle of the overlap of classes is through the three fallacies of the overlap. These fallacies are committed under the following conditions.

The first is the fallacy of precarious margins. This fallacy assumes that the overlap between classes can be trusted not to spread and affect the other species in the concept in question. It posits that beyond the area of the overlap, there exists a marginal space in which the instances of the genus exhibit only one of the specific forms, remaining uncontaminated and untainted by the presence of the other species. This fallacy is called precarious margins "because once the overlap is admitted in principle there is no ground for assuming that the overlap will stop at any particular point" (Collingwood, 1933a, 48).

The second is the fallacy of identified coincidents. Given that the overlap is in principle unlimited, this fallacy happens when it is thought that the overlap only occurs in one particular concept, even if there are two or more concepts involved. This is valid if such concepts have the same extension or corresponding group of instances. However, this stance does not acknowledge the possibility of a categorically similar group of instances or extensions that have two or more different concepts. The false principle at work in this fallacy is that the absence of difference of extension between two concepts is considered equivalent to having an identical concept, consequently treating the intensional differences between concepts as irrelevant or unnecessary. As Collingwood holds, "The false principle at work in them is that, where there is no difference in the extension of two concepts, there is no distinction between the concepts themselves" (Collingwood 1933a, 49).

The third is the fallacy of false disjunction. Collingwood explains that the two foregoing fallacies "are alternative applications of a single principle which, however true in exact and empirical science, is false in philosophy: the principle that when a generic concept is divided into its species there is a corresponding division of its instances into mutually exclusive classes" (Collingwood 1933a, 49). This is why this fallacy is the genus of the two previously mentioned fallacies. Moreover, the fallacies stand for the error of applying the theory of classification in science to concepts found in the realm of philosophy. Specifically, the fallacy of precarious margin and the fallacy of identified coincidents are its applications. To be more precise, the fallacy of precarious margin is the positive application of the fallacy of false disjunction, while the fallacy of identified coincidents is the negative counterpart. This is so because a disjunctive proposition follows the principle that any instance of a generic concept must fall either in one or in another of its specific classes. Its non-recognition is false because the overlap may indefinitely occur at any area, which is positively assumed to be non-consequential to its extension from the standpoint of the fallacy of precarious margins. The non-recognition of the principle of a disjunctive proposition is also an error since the overlap may extend to an undetermined species of a genus. This point, however, is negatively reduced to a singular concept when one assumes that it is not possible to have a differentiated concept for the same instances. When this reduction happens, one commits the fallacy of identified coincidents (Collingwood 1933a, 49). 
Overall, the presence of these fallacies provides insight into an important rule of philosophical method - that is, one should be attentive to false disjunctions of concepts since philosophical concepts are always expected to converge and overlap. In addition, our discussion on the nature of overlapping forms and the fallacies that may emerge from its non-recognition allows us to conclude that philosophy cannot set before itself, as an end, the classification, and division of its subject matter similar to that in exact and empirical sciences. The logical structure of philosophical concepts-owing to the overlap of its species — can only be provisionally classified and divided. This means that whatever philosophical thinking entails, it essentially implies a constant revision and reflection of its position. Philosophy's method of classification is always assessed and evaluated in the light of its tentatively arrived at conclusions (Collingwood, 1933, 48-53).

\section{A PHILOSOPHICAL APPROACH TO FOLK CATHOLICISM}

\section{Between Lynch and Ileto}

A study on Folk Catholicism in the country can be approached from two vantage points: Lynch, S.J. (1975) and Ileto (1979). Lynch challenges the Catholic Church's one-dimensional treatment of folk-related practices. By privileging the universal doctrines of the Catholic Faith, the church, according to Lynch (1975, 227228), subscribes to a simplistic dichotomy between official and non-official positions. The official category refers to stances and practices prescribed and recommended, while the non-official domain is regarded as tolerated, disapproved, or condemned. Lynch $(1975,227-228)$ argues that with such typology, folk-related activities have long been considered under the non-official and tolerated-disapproved domains. This is the unfortunate treatment of Folk related activities and experiences such as Folk Catholicism.

Citing Vatican II, Lynch presents the dichotomy between the official and nonofficial promulgations of the church and interprets that it is crucially retained, yet the folk-related instances/occasions/activities are approached from a different light - that of dialogue and reflexivity. This means that instead of conversion, which is stressed in the Pre-Vatican II, traditional/indigenous religiosity is considered as a possible location where the Catholic Church can have a better understanding of her disposition towards local/indigenous forms of spirituality. Lynch $(1975,237)$ stresses that the church should try to look into folk-related practices that can help deepen Filipino religiosity. However, a critical interpretation of this position will reveal the possibility of being unready to affirm the possible substantive overlap between local/traditional practices and the teachings of the Catholic Church. In this regard, it can be said that Catholicism may still be regarded as a thin veneer that coats Folk Catholic practices. This position remains cold, unready, or worried about the possibility of acknowledging the latent capacity of indigenous spirituality to criticize Catholic beliefs and practices. This is where the position of Mojares $(1993,448)$ can be underscored, noting that such possible fear can be taken to mean as a "universalizing and delocalizing strategy."

Also diverging from the possible criticism, Bulatao (1992) stresses the foundational role of internal freedom within the process of inculturation. Here, he 
underscores the importance of giving the indigenous groups time and space to appropriate the teachings of the church creatively. On this note, Bulatao (1992) hopes that the position of the church will enrich and not suffocate the latent values in an indigenous location. This is a point that opens up various meeting points between the traditional and Catholic practices in the celebration and conduct of thanksgiving rituals. As the capacities inherent in the location of the overlap in Folk Catholicism is further reflected, Lynch's stress on the Church's role of continuously trying to find ways of making the teachings of the Catholic faith known and propagated in a dialogical way can be deepened. This position also echoed in Mojares' (1993, 448) critical treatment of Mercado's biography of Ayatumo - a Boholono child deprived of substantive historical face and footing to highlight his conversion process from being an Indio to a disembodied Catholic soul.

Ileto, on the other hand, holds that Folk Catholicism is a location of agency and resistance against domineering positions (1979, 255-56). The universal church as a highly organized religious institution, for instance, has the tools, experience, and influence to eradicate/alter/change indigenous forms of religiosity. From such a perspective, Folk Catholicism is a local and creative way of defying the pressures of the more dominant expressions of religiosity. This is where the distinction between the local church and universal church also unfolds. While the universal church is represented by the Spanish colonial clergy, the local church becomes a subversive effort to protect emerging local forms of faith. This is how the 'Folk' aspect in Folk Catholicism gains a two-pronged yet intersectional meaning. Reminiscent of Mojares' (1993, 449-50) position, the historicity and particularity of things, ideas, experiences act as the built-in protest to any form of metaphysical universalizing. In describing her description of Mercado's representation of Ayatumo's biography, for instance, showcases the homogenizing tendency of the universal Catholic church at the expense or deprivation of local forms of faith and historical exigencies (Mojares, 1993, 448). As an expression of resistance, Ileto's thinking, thus, frames Folk Catholicism as one of the tactics of the colonized. Attending the novena to the saints, for instance, can be construed as a tactical mimicry - imitating the rituals of the universal church while taking inspiration from the life of Christ in fighting for radical change in existing social systems. Under the banner of Ileto's position, we can include similar positions presented by James Scott (1990) in his work on the arts of resistance of the masses and Karl Gaspar's (2010) exploratory work on the dialogical coupling of the masses and the Messiah.

For Ileto, therefore, Folk Catholicism grounds the experience of rebellion and resistance within the ambit of localized universal practices and traditions of the church. This is where he makes a nuanced interpretation of Folk Catholicism as a unique location of opposition and creative assimilation. Through the meeting points, Folk Catholicism can be construed as a location of the overlap wherein the overlapping contribution of the local church challenges and appropriates the language of the dominant church. The local community of faithful cultivates a resistance that calls for a re-thinking of sorts in the way the 'Folk' and 'Catholicism' relate in Folk Catholicism. More to the point, such re-thinking means reinterpreting Folk Catholicism as a site of transformation, reflection, questions, and dialogical prayer through a disposition of critical and grounded mediation. 


\section{A Philosophical Reflection}

When philosophically considered from the perspective of Collingwood, Lynch's and Ileto's treatments of Folk Catholicism can be reinterpreted inspired by the logic of question and answer (Collingwood, 1933b, 29): (1) How can the Catholic stance cleanse/purify and rescue indigenous spirituality from Non-Official/Catholic elements and still dispose the indigenous members of the community to recognize as their own?, (2) How can the Filipinos, e.g., the local faithful uphold and defend the dignity of their experiences, the desire for freedom, and the value of their ground-based reflections while being in the midst of colonization engineered through the spectacles of the universal church?, and (3) Is there an overlap between Folk perspective-practices and the Catholic vantage point?

For the first question, Folk Catholicism is a site of either conversion approach or the passive mold. This means that the task of the universal Catholic stance is to purge Folk practices of elements that are antithetical to the Catholic bias. Hence, the desire for conversion means abandoning or questioning the worth of local practices, beliefs, and meaning in favor of positions within the universal Catholic fold. These are some implications of the split-level Christianity view. With the second question, the intent is to take advantage of the Catholic stance as a façade for practical or communal goals. In this respect, Folk Catholicism is taken to mean as a dialectic between façade and identity assertions. Noting how the tension from below is cultivated, this enabling ground works its way to appear subjugated or defeated. However, this form of appearance is not the reality that constitutes the Folk ideas, values, and practices. For the third query, the position is to affirm the agency from both Folk and Catholic positions. In this way, the blurring of boundaries or the overlap is embraced. The fear of the uncertain is mitigated by the excitement to learn new things from the other. Thus, this open-minded stance overrides the attachments to previously held positions that may either tighten the grip of the opposition between the Folk aspect and Catholic element in a Folk Catholicism. This means that the appearance and reality in Folk Catholicism are not construed as oppositional terms. Both aspects can contribute to the reconstituting space that emerges within the midst of the overlap in Folk Catholicism.

\section{Overcoming the Three Fallacies}

With the principle of the overlap, the binary treatment of Folk Catholicism is reconstrued. If Folk Catholicism is re-built on a philosophical foundation through Collingwood's principle of the overlap of classes, it somehow gains new capacities to withstand the three fallacies.

(1) The fallacy of precarious margins is avoided by stating that in Folk Catholicism, the contribution of local spirituality and the local church to the pilgrim of the universal church is in effect yet only needs to be acknowledged. Within the ambit of the principle of the overlap, the locale is given time and is invited to reflect on its unique experiences and participation in this journey of the Church towards God's Kingdom. This is where Bulatao's (1992) notion of internal freedom is given a philosophical take by introducing the concept of blurring of boundaries as a 
requirement for such type of freedom to commence and unfold. This stance also challenges split-level theologies to make a clearer position by articulating one's fears and uncertainties which are consequent experiences when one is in the midst of blurring boundaries. In the case of Ileto (1979), the church's universal teachings and practices are no longer recognized as cover or cloak from which people can hide their ideas, struggles, or aspirations. The blurring of boundaries means that, at the minimum, the double-edged treatment of the presence of the church necessitates the church's transformative presence within itself and brings forth a type of presence that disposes people to question binary and oppositional systems or forms of thinking.

(2) The fallacy of identified coincidents is also avoided when the Church is open to admit that she is overlapping with the faith experiences of the locale and that a local church can unfold. This means that the church does not simply say that the folk spirituality one-sidedly overlaps with her camp. With the principle of the overlap, the Church needs to recognize that if she wants to create a pilgrim church, she needs to suspend her ivory tower and descend in the everydayness of the life of the people particularly the local community and their experiences. In the language of Bulatao (1992), for instance, such an approach is the path of Filipino Theology, given that the theologian is invited to discover his/her transformative freedom in integrating his/her 'folk' ways into a theology of spirituality. Otherwise, the role of the folk beliefs and practices will remain at the periphery of a universal theology. It is this peripheral treatment of either folk or Christian elements which the principle of overlap confronts and challenges.

(3) For the fallacy of false disjunction, this is circumvented when the Church does not think of and approach folk spirituality in mutually exclusive terms. The logical operator 'either or' does not have space in a Church that wants to authentically journey with the people. The church must be a role model to the rest of the sectors/institutions of the country towards the indigenous groups, for instance, being the most marginalized sector, by speaking the language of inclusivity and not of false disjunction. Thus, in taking full advantage of the principle of the overlap of classes, the location carved by the blurring of boundaries is an emerging ground which a philosophical approach to Folk Catholicism finds its home. In relation to the different positions to Folk Catholicism, this philosophical approach encourages each perspective to be more circumspect of its thought position and remain watchful of its assumptions. This is the lingering philosophical task within the Collingwoodian frame of the principle of the overlap of classes. In so doing, the blurring of boundaries is heightened and is recognized as a productive resource for critical and liberating discourse.

\section{CONCLUSION}

What Collingwood's principle of the overlap of classes contributes as an approach to Folk Catholicism is to showcase the principle's capacity to function as the condition upon which Folk Catholicism can grow as a discourse. In overcoming the three possible fallacies in discussing Folk Catholicism, the proposed new approach provides a philosophical vantage point in engaging the historical-sociological positions and theological perspectives on syncretism. In suggesting a philosophical 
vantage point, the proposal also means that Collingwood's principle of the overlap of classes is tasked to affirm some limits in both historical-sociological and theological positions, and reveal/suggest ways of incorporating their strengths in the philosophical exploration. A case in point is the principle of the overlap's expectation that the two approaches re-examine their assumptions and re-investigate the truth-reach of their claims with regard to Folk Catholicism.

Also inspired by Collingwood's scale of understanding, Folk Catholicism seen within the purview of the principle of the overlap presents itself as another way of comprehending Folk Catholicism as it is now capable of arranging and making another sense of these queries: (1) How can the Catholic stance cleanse/purify and rescue local spirituality from non-official/Catholic elements and still dispose the members of the community to recognize as their own?, (2) How can the Filipinos, e.g., the Indigenous Groups, uphold and defend the dignity of their freedom, and the values of their traditional practices, in the midst of colonization engineered through the spectacles of religion?, and (3) Is there a productive overlap between Folk practices and the Catholic vantage point in Folk Catholicism? Through the principle of the overlap of classes, these questions gain new dimensions, and meanings which is a primary goal of philosophical thinking, according to Collingwood - to better understand questions and become more mindful of thought assumptions or presuppositions.

\section{REFERENCES}

Bulatao, Jaime C. 1992. Phenomena and their interpretation: Landmark essays 1957-1989. Quezon City: Ateneo de Manila University Press.

Collingwood, Robin George. 1933a. An essay on philosophical method. London: Oxford University Press

Collingwood, Robin George. 1993b. An Autobiography. Oxford: Clarendon Press.

Gaspar, Karl M. 2010. The masses are Messiah: Contemplating the Filipino soul. Quezon City: Institute of Spirituality in Asia.

Hierbert, Paul. G., Daniel R. Shaw and Tite Tiénou. 1999/2000. Responding to splitlevel Christianity and folk religion. International Journal of Frontier Missions 16 (4): 173-181.

Ileto, Reynaldo. C. 1979. Pasyon and revolution: Popular movements in the Philippines, 1849-1910. Quezon: Ateneo de Manila University Press.

Lynch, Frank. 1975. Folk Catholicism in the Philippines. In Society, culture, and the Philippines. Edited by Mary Racelis Hollnsteiner, Maria Elena Chiong, Anicia Paglinawan, and Nora Villanueva. Quezon: Institute of Philippine Culture, 2: 227238. Ateneo de Manila University.

Mojares, Resil B. 1993. The life of Miguel Ayatumo: A sixteenth-century Boholano. Philippine Studies 41(4): 437-458.

Scalice, Joseph. 2018. Reynaldo Ileto's Pasyon and revolution revisited, a critique. Sojourn Journal of Social Issues in Southeast Asia. Available at: doi: 10.1355/sj33-1b. Accessed: July 12, 2019. 
Schumacher, John N. 1984. Syncretism in Philippine Catholicism: Its historical causes. Philippine Studies 32 (3): 251-272.

Scott, James. 1990. Domination and the arts of resistance: Hidden transcripts. New Haven and London: Yale University Press.

Vergote, Antoine. 1982. Folk Catholicism: Its significance, value and ambiguities. Philippine Studies 30 (1): 5-26. 